\title{
Does economic growth positively affect income inequality in China?
}

\author{
Xun Ding, Tian Dong, Yanjie Xu, Zhi Zheng
}

\begin{abstract}
This report focuses on the relationship between the economic growth and income inequality in China. The hypothesis is that economic growth led to an increase in income inequality in China. The alternative hypothesis is that economic growth led to a decrease in income inequality in China. After analysing GDP per capita and the GINI index from World Bank, the results show a positive relationship between economic growth and income inequality. Additionally, this report also would measure the influence of monopoly power and the disposable income of urban/rural households to further support the hypothesis.
\end{abstract}




\section{Introduction and hypothesis}

Income inequality has become one of the most serious and compelling social issue in modern China. Under the rapid economic growth in China, more and more economists emphasise the importance of the balance between economic growth and income equality. As Li (1993) states that China has failed to achieved the objective of income equality though achieved the objective of fast economic growth. Existence of a large income inequality gap may cause a raise in crime rate and shatter the social stability. Widening income inequality also has significant implications for economic growth and macroeconomic stability since, political decision making power is controlled by the hands of enormously rich people, which lead to a suboptimal use of social resources. As a result, it may reduce economic stability and raise financial crisis risk. (Dabla-Norris, Kochhar 2015)

The hypothesis in this report is that economic growth led to an increasing of income equality in China. The alternative hypothesis is that economic growth led to a decreasing of income equality in China. In order to test the hypothesis, data such as the GINI index and GDP per capita have been collected to illustrate the relationship between economic performance and the income equality gap in China. Furthermore, we use a measure of monopoly power over and the disposable income of urban/rural households over a specific time for further test of the hypothesis. The hypothesis would be accepted if we find a positive relationship between the GINI index, monopoly power, the urban-rural wage gap and GDP per capita.

\section{Theory and literature review}

From several decades ago, economists found some relationship between economic development and income inequality.

In 1954, Arthur Lewis published an important article called "Economic Development with Unlimited Supplies of Labour'. In his article, he state that the economic growth would firstly arise in the urban modern industrial sector during the initial period of economic growth. On the 
contrary, the traditional country sector would maintain at subsistence, hence driving inequality between the two sectors. The model was to be called "Dual sector Model" or "Lewis Model".

\section{Figure 1: Kuznets curve}

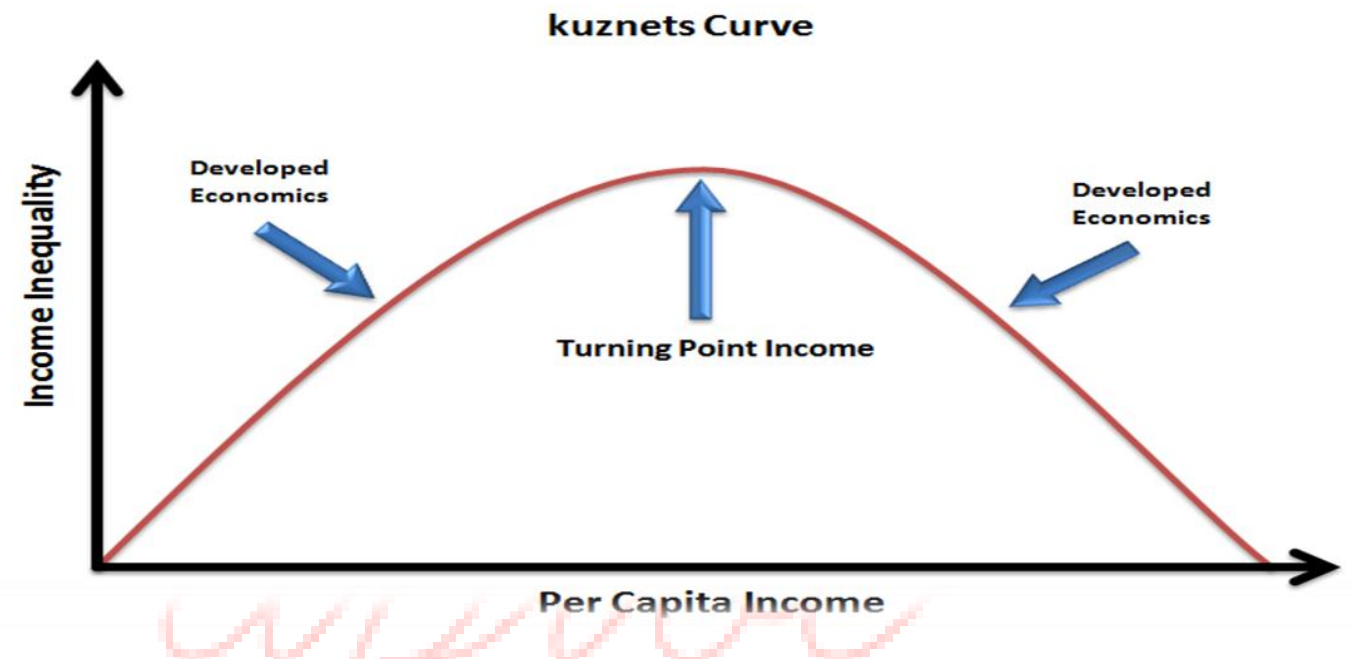

Source: Kuznets, 1955 'Economic Growth and Income Inequality'

Kuznets (1955) firstly made the research about the correlation between economic growth and income inequality which was to be represented as "Kuznets Curve" as shown in Figure 1. He stated that: at the beginning of economic growth, income inequality would be increasing. And then it would become steady when economic growth reaches the 'mid-term'. Finally income inequality would decrease during the later stage of economic growth.

However, two Chinese economists named Zhao and Li (1999) declared that the Kuznets Curve was not suitable for the Chinese economic situation since inequality was driven primarily by an urban-rural gap. The following economists Hong (1995), Lin (2000), Li (2000), Lu (2000) 
thought that the economic policies which favoured urban growth would be the significant reason which leaded to Chinese income inequality.

In 2002, Zhou found the positive relationship between economic growth and income equality which used GINI data from 1978-1995. Wang and Fan (2005) tested "Kuznets Curve" again; using Panel data they found that the situation of the Chinese economic did not have the characteristic of the "Kuznets Curve". However, the relationship just accorded with the increasing period of the curve. They could not find the decreasing period of the curve. In addition, they said the income inequality can also be affected by society policies such as redistribution of income, social security system, infrastructure regime and so on.

Lu (2005) found that there was a negative because of the interaction of income equality, investment, education and economic growth. In 2008, Wang and Ouyang used nonlinear threshold cointegration model and found that there was a positive relationship during 19921999, but it turned into negative after 1999. Liu and Fu (2005) used the data after Chinese reform and opening - up policy found that GINI increased with the economic growth which showed a positive relationship.

Due to the argument of Kuznets Curve, many economists such as Gallet (2004) and Tribble (1999) thought the curve should be $S$-shaped instead of an inverted-U shown as Figure 2. In the S-shape, there were two turning points which means the income inequality would decrease when reach point A and increase again when reach point B. It stated that Kuznets' inverted Ucurve should be turned into S-shaped curve where the turning point $\mathrm{A}$ is associated with transition from "Two- sectors" which is agriculture to manufacturing and turning point B is the structural transition from manufacturing to service.

In addition, a Chinese economist named Chen (2010) compared the GINI both of city residents and rural residents with per capita GDP, used cointegration and Granger causality; he found that urban-rural income equality and economic growth had bidirectional causality - the relationship was not obvious. 
Figure 2: S-shape curve

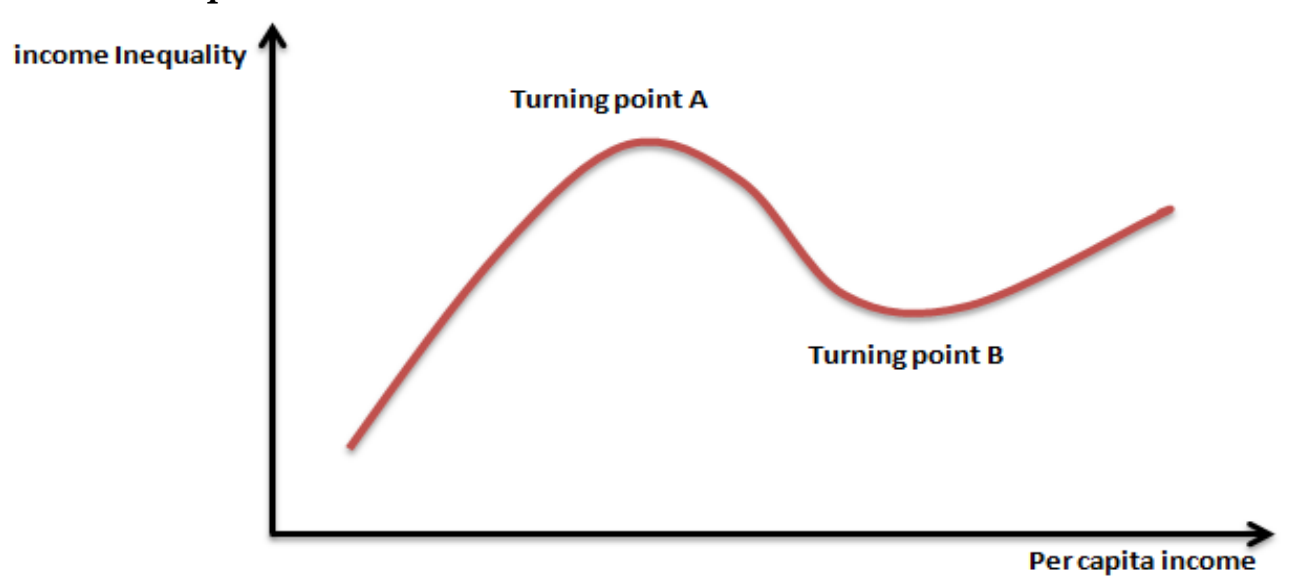

Source: Gallet \& Gallet, 2004, 'U.S. growth and income inequality: evidence of racial differences'

\section{Analysis}

\section{1: Data selection and collection}

GDP per capita and the GINI coefficient are commonly used to represent economic growth as well the income inequality. In order to test and verify the hypothesis and alternate hypothesis between these two variables, this report also collected as much data as available. However, as a matter of fact that the government has not promulgate the official statistics for recent years. And part of the GINI coefficient were extracted form a professional secondary resource. By accounting for these factors, this report ultimately selected the data sets from 1997 to 2010.

Table 1 (showed below) are the data set of GDP per capital and the Gini Coefficient. According to the data displayed below, it clearly indicates that the data from year 1997 to 2010 which showed a dramatic increase. This increasing trend illustrates China's economy developing rapidly and steadily. On the other hand, in order to investigate and analyse the relationship 
between GDP per capita and the GINI coefficient, Table 2 shows a very clear relationship of these two variables for all those different years. From 1997, it shows that with a lowest GDP per capita correspond a lowest GINI coefficient. In addition, the analysis also used the scatter plot and regression analysis to verify and validate our hypothesis.

\section{Table 1: Data}

\begin{tabular}{|r|r|r|}
\hline Year & GDP per capita & GINI coefficient \\
\hline 1997 & 779 & 0.398 \\
\hline 1998 & 826 & 0.403 \\
\hline 1999 & 870 & 0.416 \\
\hline 2000 & 955 & 0.438 \\
\hline 2001 & 1047 & 0.447 \\
\hline 2002 & 1142 & 0.450 \\
\hline 2003 & 1281 & 0.479 \\
\hline 2004 & 1498 & 0.473 \\
\hline 2005 & 1740 & 0.485 \\
\hline 2006 & 2082 & 0.487 \\
\hline 2007 & 2673 & 0.484 \\
\hline 2008 & 3441 & 0.491 \\
\hline 2009 & 3800 & 0.490 \\
\hline 2010 & 4515 & 0.481 \\
\hline
\end{tabular}

Sources: GDP, World bank,

<http://databank.worldbank.org/data//reports.aspx?source=2\&country=\&series=NY.GDP.PCAP.CD\&period=>; 1997-2001 are from Ravallion and Chen (2007), 2002 from Gustafsson et al. (2008), 2003-2010 from the Staticta, <http://www.statista.com/statistics/250400/inequality-of-income-distribution-in-china-based-on-the-gini-index/>.

On condition that the main hypothesis is supported, the dots in scatter plot should show a positive relationship which slope from lower left to the upper right. 


\section{2: Regression analysis}

Before we start our analysis, we started with correlation test. As shown in Table 3, there was a significant positive relationship between GDP and GINI, Rural and GDP, as well as Rural and GINI.

\section{Table 2: Correlations}

Correlations

\begin{tabular}{|ll|r|r|r|r|r|r|}
\hline & & \multicolumn{1}{|c|}{ GDP } & \multicolumn{1}{c|}{ GINI } & \multicolumn{1}{c|}{ Lerner } & disposable & annual & rural \\
\hline GDP & Pearson Correlation & 1 & $.706^{* *}$ & .466 & $.990^{* *}$ & $.998^{* *}$ & $.684^{* *}$ \\
& Sig. (2-tailed) & & .005 & .093 & .000 & .000 & .007 \\
& $\mathrm{~N}$ & 14 & 14 & 14 & 14 & 14 & 14 \\
\hline GINI & Pearson Correlation & \multicolumn{1}{|c|}{$.706^{* *}$} & 1 & .317 & $.793^{* *}$ & $.728^{* *}$ & $.985^{* *}$ \\
& Sig. (2-tailed) & .005 & & .269 & .001 & .003 & .000 \\
& $\mathrm{~N}$ & 14 & 14 & 14 & 14 & 14 & 14 \\
\hline Lerner & Pearson Correlation & .466 & .317 & 1 & .482 & .484 & .307 \\
& Sig. (2-tailed) & .093 & .269 & & .081 & .079 & .286 \\
& $\mathrm{~N}$ & 14 & 14 & 14 & 14 & 14 & 14 \\
\hline disposable & Pearson Correlation & $.990^{* *}$ & $.793^{* *}$ & .482 & 1 & $.994^{* *}$ & $.775^{* *}$ \\
& Sig. (2-tailed) & .000 & .001 & .081 & 14 & .000 & .001 \\
& $\mathrm{~N}$ & 14 & 14 & 14 & 14 & 14 & 14 \\
\hline annual & Pearson Correlation & $.998^{* *}$ & $.728^{* *}$ & .484 & $.994^{* *}$ & 1 & $.705^{* *}$ \\
& Sig. (2-tailed) & .000 & .003 & .079 & .000 & & .005 \\
& $\mathrm{~N}$ & 14 & 14 & 14 & 14 & 14 & 14 \\
\hline rural & Pearson Correlation & $.684^{* *}$ & $.985^{* *}$ & .307 & $.775^{* *}$ & $.705^{* *}$ & 1 \\
& Sig. (2-tailed) & .007 & .000 & .286 & .001 & .005 & 14 \\
& $\mathrm{~N}$ & 14 & 14 & 14 & 14 & 14 & 14 \\
\hline
\end{tabular}

${ }^{* *}$. Correlation is significant at the 0.01 level (2-tailed).

Table 3 represents the regression analysis. The trend line produced with slope of 0.00002 and $\mathrm{R}$ square of 0.499 . GDP per capita was found to be a significant positive predictor of GINI, such that higher levels of GDP predicted higher GINI, $\beta=.71, p=.005$. GDP uniquely 
accounted for $50 \%$ of the variance of in GINI coefficient. The equation of this trend line is $\mathrm{Y}=0.00002 \mathrm{x}+0.4222$, suggesting a positive relationship between GDP per capita and GINI coefficient.

In addition there is some research showing that after year 2008 the GINI coefficient has a slight down slope. It might be due to financial crisis or government's regulation such as setting a higher minimum wage and increasing the individual income tax threshold. According to the Kuznets curve, there is reason to believe that in the coming decades as long as GDP per capita keeps increasing, the GINI coefficient will keep decreasing as well.

\section{Table 3: Regression Results}

\begin{tabular}{|c|c|c|c|c|c|c|c|c|c|}
\hline \multirow[b]{3}{*}{ Madel } & \multirow[b]{3}{*}{$\mathrm{R}$} & \multicolumn{7}{|c|}{ Model Summary } & \\
\hline & & & & & & & Statis & & \\
\hline & & quare & $\begin{array}{l}\text { Adjusted R } \\
\text { Square }\end{array}$ & $\begin{array}{l}\text { Std. Error of } \\
\text { the Estimate }\end{array}$ & $\begin{array}{c}\text { R Square } \\
\text { Change }\end{array}$ & F Change & df1 & $\mathrm{df2}$ & Sig. F Change \\
\hline 1 & $.706^{2}$ & .499 & .457 & .024622 & .499 & 11.953 & 1 & 12 & .005 \\
\hline
\end{tabular}

a. Predictors: (Constamt), GDP

\begin{tabular}{|c|c|c|c|c|c|c|}
\hline \multicolumn{7}{|c|}{ ANOVA $^{a}$} \\
\hline & & $\begin{array}{l}\text { Sum of } \\
\text { Squares }\end{array}$ & df & Mean Square & $\mathrm{F}$ & Sig. \\
\hline \multirow[t]{3}{*}{1} & Regression & .007 & $\overline{1}$ & .007 & 11.953 & $.005^{b}$ \\
\hline & Residual & .007 & 12 & .001 & & \\
\hline & Total & .015 & 13 & & & \\
\hline
\end{tabular}

a. Dependent Variable: GINI

b. Predictors: (Constant), GDP

Coefficients $^{\text {a }}$

\begin{tabular}{|c|c|c|c|c|c|c|c|c|}
\hline \multirow{2}{*}{\multicolumn{2}{|c|}{ Model }} & \multicolumn{2}{|c|}{ Unstandardized Coefficients } & \multirow{2}{*}{$\begin{array}{c}\begin{array}{c}\text { Standardized } \\
\text { Coefficients }\end{array} \\
\text { Beta }\end{array}$} & \multirow[b]{2}{*}{$t$} & \multirow[b]{2}{*}{ Sig. } & \multicolumn{2}{|c|}{$\begin{array}{c}95.0 \% \text { Confidence Interval for } \\
\text { B }\end{array}$} \\
\hline & & $\mathrm{B}$ & Std. Error & & & & Lower Bound & Upper Bound \\
\hline 1 & (Constant) & .422 & .012 & & 33.927 & .000 & .395 & .449 \\
\hline & GDP & $1.918 E-005$ & .000 & .706 & 3.457 & & .000 & .000 \\
\hline
\end{tabular}




\section{3: Further variables}

In order to further support the hypothesis, this report also analyses rural-urban income gap and monopoly power as explained below.

(1) Income gap

In order to assess whether the Lewis model explains inequality growth in China, we collected data sets of net income per capita in urban and rural of China. ${ }^{1}$ Figure 4 indicates a positive relationship of slope 0.0002 and R square 0.4682 . GDP group was also found to be a significant positive predictor of urban-rural group, such that higher levels of GDP predicted higher urbanrural group, $\beta=.69, \mathrm{p}=.007$. GDP uniquely accounted for $13 \%$ of the variance of in urban rural group. There was no significant relationship between Lerner index and GDP also between GDP and high-low income gap.

We also collected data of the lowest $10 \%$ and highest $10 \%$ of disposable income of urban households per capita. Figure 5 illustrates the gap were became bigger along with the economic growth.

Our data support the S-Shape hypothesis for the period 1991-2010 also as shown in Figure 5. The turning point occurs at 2005 while the second at 2008. The curve starts increasing in the year 2002 and it shows a declines after the year 2005. The S-Shape is again increased from the year 2007.

As a result, the income gap is also a reason related to the hypothesis.

\footnotetext{
${ }^{1}$ Source--- National Bureau of Statistics, <http://data.stats.gov.cn/english/easyquery.htm?cn=C01>
} 
Figure 4: Relationship between GDP per capita and urban-rural gap

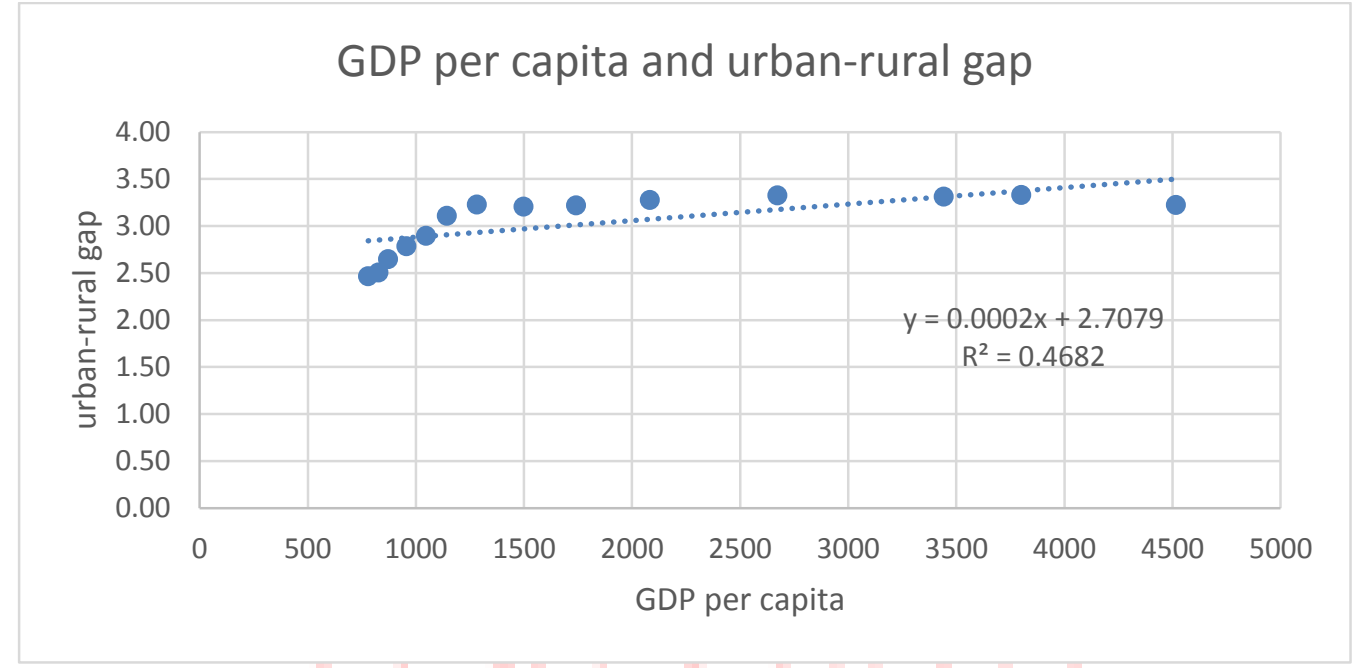

Figure 5: Relationship between GDP per capita and highest-lowest gap

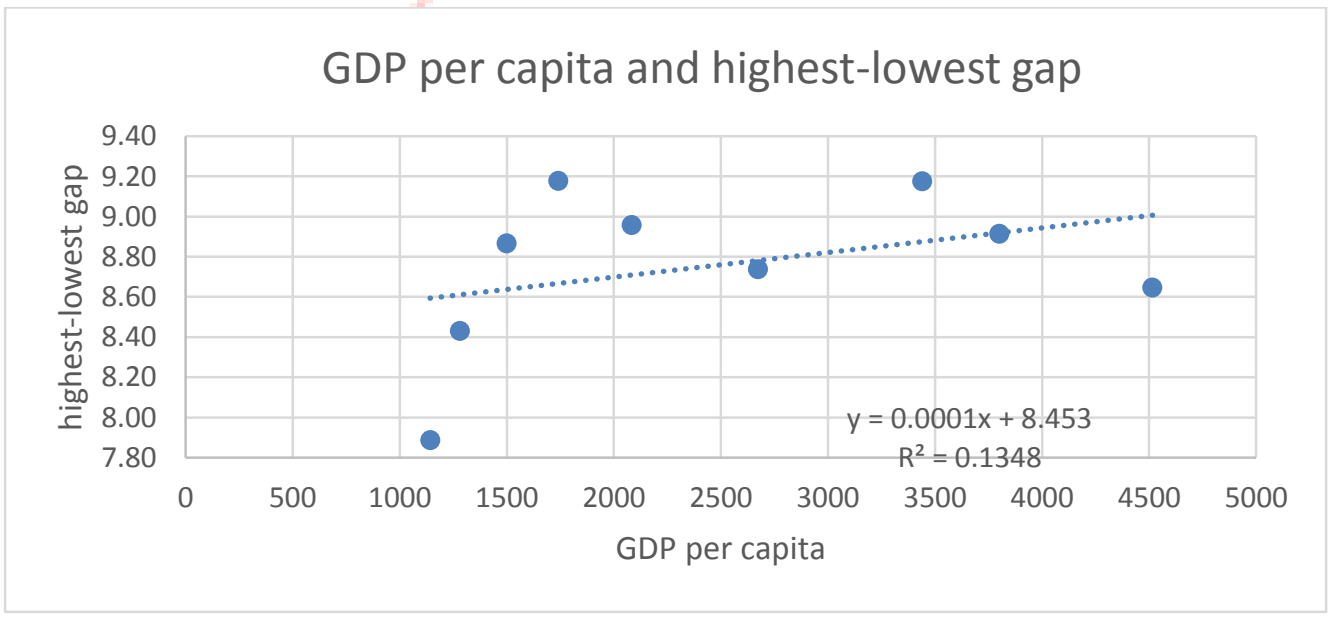


(2) Monopoly level

Lerner index uses price elasticity of demand to measure market power, it is a great way to measure monopoly power levels. Due to resource constraints our Lerner index is based only on banks.

We used the Lerner Index from year 1997 to 2010 compared with GINI coefficient and GDP per capita as well. ${ }^{2}$ After analysing these two scatter plot charts (Figures 6 and 7), we find that with the development of an economy, the Lerner index is also increasing. Besides, between the GINI coefficient and Lerner index there also shows a positive relationship. On the other hand, throughout trend of the scatter plot of GDP per capita \& Lerner index, it further validates our hypothesis that the relationship between GDP per capita and GINI coefficient are in a positive relationship. Consequently, monopoly part of the reason that has led to inequality increasing.

\section{Figure 6: Relationship between GDP per capita and Lerner Index}

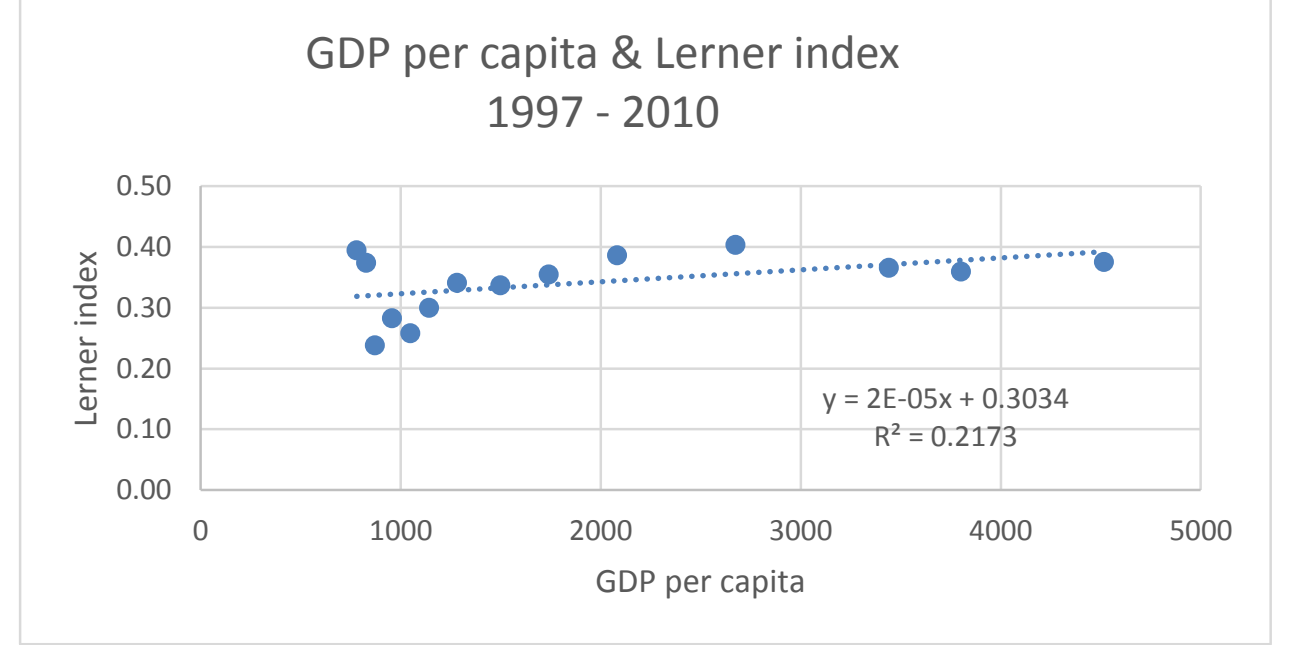

\footnotetext{
${ }^{2}$ Source--- Economic Research, <https://research.stlouisfed.org/fred2/series/DDOI04CNA066NWDB>
} 
Figure 7: Relationship between Lerner index and GINI index

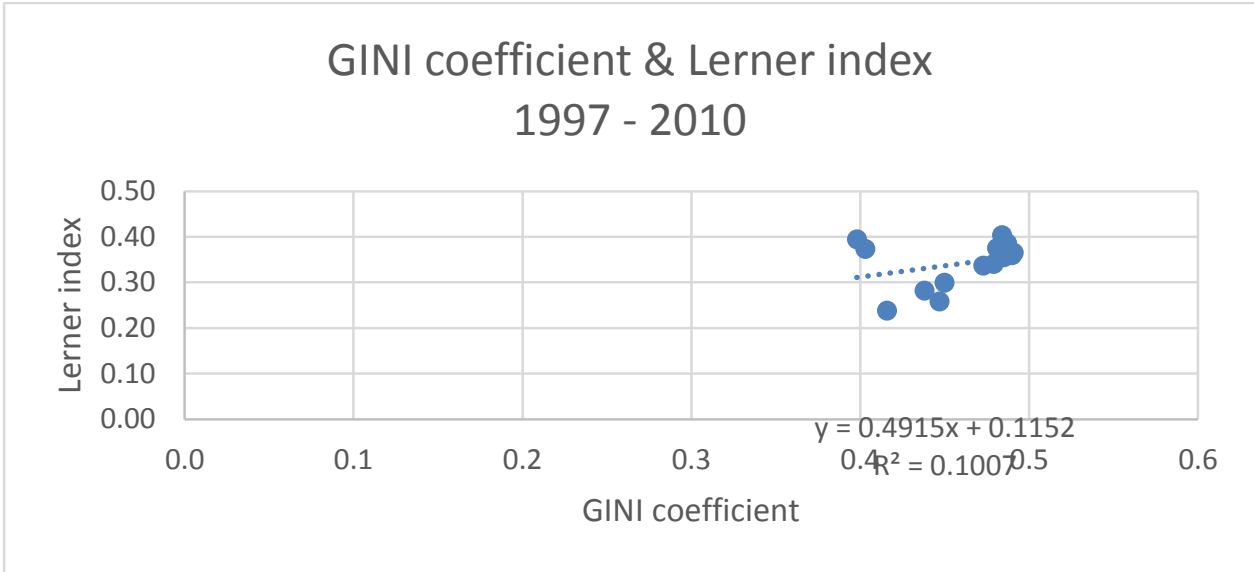

\section{Limitations}

The main limitation in this research is data collection. The release of Chinese official date is limited, and it created small issue for matching data. Also, this report has not considered the government intervention. The 2008 financial crises also have a slight influence for the variables test. To be specific, after the financial crisis in 2008, the US domestic demand decreased sharply. US as the largest import country for china it absolutely inhibiting the growth of Chinese exports. Therefore, the Chinese foreign trade enterprises are facing fearful operating difficulties, some companies even closed down. The stock market fell significantly, exchange rates, capital markets, financial industry have been seriously affected. Venture capital market intensifies, but also led to the reduction of demand for labor and increased the unemployment rate. In order to respond to the financial crisis, the Chinese government has improved by deepening financial reform financial risk resilience, strengthened infrastructure construction, expanded domestic demand, and positively opened international markets, stabilized exports, boosted domestic consumption and stimulated economic development. Moreover, the Chinese government has also been seeking global cooperation to combat the crisis together. The most 
important point is China has also reformed the foreign trade development mode, reduced many adverse effects on its external market, and resolved financial crises. So that China's economy sustained, healthy and stable developing.

\section{Conclusion}

Through analysis of the data, we find a positive relationship between GINI index and GDP per capita in China. Moreover, the result of further variables tests also show an increase in the urban-rural wage gap as well as the Lerner index (for banks). As a result, the hypothesis which is the economic growth led the income inequality increasing in China is accepted.

\section{References}

Anping C, 2010, 'China's income gap and economic growth of the panel Cointegration And causal research investigate', retrieved 15 July 2015.

Dayong H, Yifu L, Zuojun L \& Ming L, 2000, 'Economic growth and evolution of the income gap between urban and rural areas', retrieved 10 August 2015.

Era D, Kalpana K, Frantisek R, Nujin S \& Evridiki T, 2015 'Causes and Consequences of Income Inequality: A Global Perspective', retrieved 12 August 2015, EBSCOhost.

Gallet, C, \& Gallet, R 2004, 'U.S. growth and income inequality: evidence of racial differences', The Social Science Journal, vol.41, pp. 43-51, retrieved 7 July 2015, ScienceDirect.

Gustafsson B, Yue X, Terry S \& Li S, 2008,'Explaining Incomes and Inequality in China', Cambridge University Press, retrieved 5 August 2015, EBSCOhost.

Kuznets, S, 1955, 'ECONOMIC GROWTH AND INCOME INEQUALITY', American Economic Review, vol.45, no.1, p. 1, retrieved 10 July 2015,Business Source Complete. 
Lewis, A. 1954, 'Economic Development with Unlimited Supplies of Labour', The Manchester School, vol. 22, no. 2, pp. 139-191, retrieved 20 August 2015, EBSCOhost.

Li L \& Chen F, 2005, 'China's economic growth and income distribution relationship of cause and effect relation analysis', retrieved 10 August 2015.

Ming L, 2005, 'Globalization and the income gap between regions', pp. 47-57, retrieved 8 August 2015.

Renwei Z \& Shi L, 1999, 'the residents' income distribution in China', retrieved 10 August 2015.

Ravallion M \& Chen S, 2007, 'China's (Uneven) Progress Against Poverty', Journal of Development Economics, vol. 82, no. 1, pp.1-42, retrieved 7 August 2015, EBSCOhost.

Shao P, Zhi G \& Ou Y, 2008, 'Measurement of the rural and urban income gap and its effect on economic growth', retrieved 15 August 2015.

Shi L. , 1993, "Changes in income inequality in China in the past three decades[J]." retrieved 30 November 2015.

Tribble Jr, R 1999, 'A Restatement of the S-Curve Hypothesis', Review Of Development Economics, vol.3, no.2, p. 207, retrieved 25 July 2015, Business Source Complete.

Wenxing Z, 2002, 'China's urban residents' income distribution and economic growth relations empirical analysis', retrieved 10 August 2015.

Xiao L \& Gang F, 2005, 'China's income gap analysis of the situation and influence factors', retrieved 10 August 2015. 